Check for updates

Cite this: Chem. Sci., 2018, 9, 8542

๑ All publication charges for this article have been paid for by the Royal Society of Chemistry

\title{
Mechanistic study of styrene aziridination by iron(Iv) nitrides $\uparrow$
}

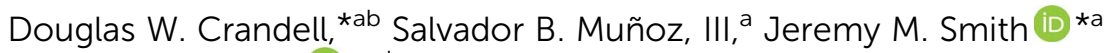 \\ and Mu-Hyun Baik (DD *cd
}

A combined experimental and computational investigation was undertaken to investigate the mechanism of aziridination of styrene by the tris(carbene)borate iron(Iv) nitride complex, $\mathrm{PhB}\left({ }^{\mathrm{t}} \mathrm{Bu} / \mathrm{m}\right)_{3} \mathrm{Fe} \equiv \mathrm{N}$. While mechanistic investigations suggest that aziridination occurs via a reversible, stepwise pathway, it was not possible to confirm the mechanism using only experimental techniques. Density functional theory calculations support a stepwise radical addition mechanism, but suggest that a low-lying triplet $(S=1)$ state provides the lowest energy path for $\mathrm{C}-\mathrm{N}$ bond formation $\left(24.6 \mathrm{kcal} \mathrm{mol}^{-1}\right)$ and not the singlet ground $(S=0)$ state. A second spin flip may take place in order to facilitate ring closure and the formation of the quintet $(S=2)$ aziridino product. A Hammett analysis shows that electron-withdrawing groups increase the rate of reaction $\sigma_{\mathrm{p}}(\rho=1.2 \pm 0.2)$. This finding is supported by the computational results, which show that the rate-determining step drops from $24.6 \mathrm{kcal} \mathrm{mol}^{-1}$ to $18.3 \mathrm{kcal} \mathrm{mol}^{-1}$ when $\left(p-\mathrm{NO}_{2} \mathrm{C}_{6} \mathrm{H}_{4}\right) \mathrm{CH}=\mathrm{CH}_{2}$ is used and slightly increases to $25.5 \mathrm{kcal} \mathrm{mol}{ }^{-1}$ using $\left(p-\mathrm{NMe}_{2} \mathrm{C}_{6} \mathrm{H}_{4}\right) \mathrm{CH}=\mathrm{CH}_{2}$ as the substrate.

Received 17th August 2018

Accepted 8th September 2018

DOI: $10.1039 /$ c8sc03677b

rsc.li/chemical-science
The metal-catalyzed transfer of nitrenes (NR) to alkenes is an appealing and concise synthetic route to aziridines that has attracted substantial efforts towards the development of efficient and versatile reaction protocols, ${ }^{7,8}$ most notably the copper-catalyzed asymmetric aziridination of alkenes by $\mathrm{PhI}=$ NTs, which leads to the formation of $N$-tosylatedaziridines., ${ }^{\mathbf{9 1 0}}$ The utility of the copper-catalyzed methodology has been demonstrated in its application to the total synthesis of (+)-agelastatin A. ${ }^{11}$ Despite this success, the nitrene transfer strategy suffers from a number of severe limitations, many of which are related to the nitrene source, which typically requires an electron withdrawing group (e.g. $\mathrm{N}$-sulfonyl) for successful alkene aziridination. While new catalysts and/or alternate nitrene sources have had some success in addressing these problems, allowing for direct access to the more desirable $\mathrm{N}-\mathrm{R}$ or $\mathrm{N}-\mathrm{H}$ substituted aziridines, ${ }^{\mathbf{1 2}-18}$ these solutions typically require expensive/toxic transition metals and/or costly/ hazardous nitrene sources.

We have previously reported that the tris(carbene)borate iron(Iv) nitride complex $\mathrm{PhB}\left({ }^{t} \mathrm{BuIm}\right)_{3} \mathrm{Fe} \equiv \mathrm{N}^{19} 1$ reacts under thermal conditions with a range of styrenes to yield the corresponding high spin $(S=2)$ iron(II) aziridino complexes $\mathrm{PhB}\left({ }^{t} \mathrm{BuIm}\right)_{3} \mathrm{Fe}-\mathrm{N}\left(\mathrm{CH}_{2} \mathrm{CH}\left(\mathrm{C}_{6} \mathrm{H}_{4} \mathrm{R}\right)\right)$ by a two-electron nitrogen atom reaction (Scheme 1). ${ }^{20}$ This is a rare instance of nitrogen atom transfer from a nitride ligand to an alkene substrate. ${ }^{21,22}$ Transition metal nitride complexes are generally unreactive towards hydrocarbons..$^{23-28}$ The aziridino ligand can be released from iron in a subsequent transformation, providing the corresponding $\mathrm{N}-\mathrm{H}$ aziridine in quantitative yield. Although not 

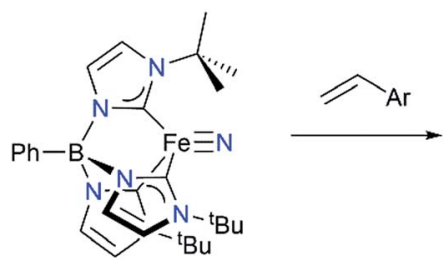

$S=0$

$$
\begin{aligned}
& \mathrm{Ar}=p-\mathrm{XC}_{6} \mathrm{H}_{4} \\
& \mathrm{X}=\mathrm{NO}_{2}, \mathrm{CF}_{3}, \mathrm{Cl}, \mathrm{H}, \mathrm{Me}, \mathrm{OMe}, \mathrm{NMe}_{2} \\
& \mathrm{Ar}=0-\left(\mathrm{CH}_{3}\right) \mathrm{C}_{6} \mathrm{H}_{4}
\end{aligned}
$$

Scheme 1

catalytic, an appealing aspect of this reaction sequence is that it demonstrates an alternative strategy to the commonly used nitrene transfer methodology for accessing synthetically useful $\mathrm{N}-\mathrm{H}$ substituted aziridines under mild conditions. Moreover, since metal nitrides are accessible from $\mathrm{N}_{2},{ }^{29}$ understanding the mechanism of this aziridination reaction may provide insight into methods for functionalizing hydrocarbons using $\mathrm{N}_{2}$ as the nitrogen atom source.

This unusual reactivity of the tris(carbene)borate iron nitride complexes has prompted us to undertake a combined experimental and theoretical study into the mechanism of aziridine ring formation. This two-electron, nitrogen atom transfer reaction is related to alkene aziridination by transition metal imido complexes. Experimental ${ }^{30-33}$ and computational ${ }^{34}$ mechanistic investigations of alkene aziridination by iron imi$\operatorname{dos}^{35}$ have generally implicated stepwise mechanisms involving radical intermediates, ${ }^{36}$ suggesting that the aziridination reactivity of $\mathbf{1}$ may occur by a similar mechanism. However, it is not clear how the greater charge of the nitride ligand and the greater covalency of the iron nitride bond will influence the energetics of the stepwise radical pathway. Styrene aziridination is also conceptually related to alkene epoxidation via oxygen atom transfer from metal oxo intermediates. ${ }^{37-40}$ Stepwise mechanisms have also been proposed for alkene epoxidation by high valent iron oxo intermediates in both heme $\mathrm{e}^{41-43}$ and nonheme ${ }^{44-49}$ environments, including pathways involving radical $^{50,51}$ and cationic intermediates. ${ }^{52,53}$ The accessibility of these mechanisms may be dictated by spin state changes, where computational studies have suggested the involvement of more than one spin surface (i.e., multistate reactivity) $)^{54}$ in the epoxidation of alkenes by cytochrome P450. ${ }^{5-58}$ Elucidating the mechanism of aziridination by $\mathbf{1}$ is expected to provide important insights into the further development of nitrogen atom transfer reactions, particularly for alkene aziridination, where similar multistate reactivity may also be important. Indeed, we note that nitrene transfer reactions of a copper complex supported by redox-active iminosemiquinone ligands have also been proposed to involve multistate reactivity. ${ }^{59}$ Additionally, multistate reactivity is noted in the posited mechanism for the cyclopropanation reaction of iron alkylidenes with alkenes. ${ }^{60}$

In this paper we report a combined experimental and computational investigation into the styrene aziridination mechanism. Experimental investigations strongly suggest a stepwise pathway, which is confirmed by the computational investigation. The latter studies also provide insight into the effect of spin state considerations on the mechanism of aziridination. These studies are important for the further development of the nitrogen atom transfer strategy for hydrocarbon functionalization.

\section{Experimental}

\section{General considerations}

All manipulations were performed under a nitrogen atmosphere by standard Schlenk techniques or in an M. Braun Labmaster glovebox. Glassware was dried at $150{ }^{\circ} \mathrm{C}$ overnight. Diethyl ether, $n$-pentane, tetrahydrofuran, and toluene, were purified by the Glass Contour solvent purification system. Deuterated benzene was first dried with $\mathrm{CaH}_{2}$, then over Na/ benzophenone, and then vacuum transfer into a storage container. Before use, an aliquot of each solvent was tested with a drop of sodium benzophenone ketyl in THF solution. All reagents were purchased from commercial vendors and used as received. Complex 1 was prepared according to a literature procedure. ${ }^{19}{ }^{1} \mathrm{H}$ NMR data were recorded on a Varian Unity 400 $\mathrm{MHz}$ or a Varian Inova $500 \mathrm{MHz}$ spectrometer at $25^{\circ} \mathrm{C}$.

\section{Mechanistic investigations}

A J-Young NMR tube was charged with $1(10 \mathrm{mg}, 0.016 \mathrm{mmol}, 1$ equiv.) and 1 equivalent of the corresponding styrene and $\mathrm{C}_{6} \mathrm{D}_{6}$ $(1.5 \mathrm{~mL})$. The ${ }^{1} \mathrm{H}$ NMR spectrum of the reaction mixture was obtained immediately after styrene. The reaction solution was heated in an oil bath at $65{ }^{\circ} \mathrm{C}$. The ${ }^{1} \mathrm{H}$ NMR spectrum of the reaction was collected at regular time intervals using a thirty second relaxation delay. Reaction plots were generated by integrating the resonances of the reactants and products for each time measurement, with the integrations normalized to residual tetrahydrofuran present in the reaction. The average of two resonances for each species was used to determine the molar concentration with an estimated error of less than $5 \%$.

\section{Computational details}

All calculations were performed using density functional theory ${ }^{60,61}$ as implemented in the Jaguar 8.1 suite of ab initio quantum chemistry programs. ${ }^{62}$ Geometry optimizations using Grimme's D3 dispersion corrections ${ }^{63}$ were performed with the B3LYP functional ${ }^{64-68}$ using the $6-31 \mathrm{G}^{* *}$ basis set with Fe represented using the Los Alamos LACVP basis set that includes relativistic core potentials. ${ }^{69-71}$ More accurate single point energies were computed from the optimized geometries along with Dunning's correlation-consistent triple- $\zeta$ basis set, ccpVTZ(-f) that includes a double set of polarization functions. ${ }^{72}$ Fe was represented using a modified version of LACVP, designated as LACV3P, in which the exponents were decontracted to match the effective core potential with triple- $\zeta$ quality. Additional single point energy calculations were done using the M06 functional. ${ }^{73}$ Vibrational frequencies were computed at the B3LYP/6-31G** level of theory to derive zero point energy and 
vibrational entropy corrections from unscaled frequencies. Entropy here refers specifically to the vibrational/rotational/ translational entropy of the solute(s), as the continuum model includes the entropy of the solvent. All intermediates were confirmed as minima on the potential energy surface having zero imaginary frequencies. Transition states were confirmed to possess only one imaginary frequency. Solvation energies were evaluated using a self-consistent reaction field (SCRF) approach based on accurate numerical solutions of the linearized Poisson-Boltzmann equation. ${ }^{74-77}$

Solvation calculations were carried out on the optimized gasphase geometries using a dielectric constant of $\varepsilon=2.284$ for benzene. As with all continuum models, the solvation energies are subject to empirical parameterization of the atomic radii that are used to generate the solute surface. We employ the standard set of optimized radii for $\mathrm{H}(1.150 \AA), \mathrm{B}(2.042 \AA), \mathrm{C}$ $(1.900 \AA), \mathrm{N}(1.600 \AA)$, O (1.600 ̊), and Fe (1.456 $)$. AF states were modeled using Noodleman's broken symmetry (BS) formalism without spin projection. ${ }^{78-80}$ The change in solution phase free energy $\Delta G(\mathrm{sol})$ was calculated as follows:

$$
\begin{gathered}
\Delta G(\text { sol })=\Delta G(\text { gas })+\Delta \Delta G_{\text {solv }} \\
\Delta G(\text { gas })=\Delta H(\text { gas })-T \Delta S(\text { gas }) \\
\Delta H(\text { gas })=\Delta E(\mathrm{SCF})+\Delta \mathrm{ZPE}
\end{gathered}
$$

$\Delta G$ (gas) is the change free energy in gas phase; $\Delta \Delta G_{\text {solv }}=$ change in free energy of solvation; $\Delta H$ (gas) $=$ change in gas phase enthalpy; $T=$ temperature (338.15 K); $\Delta S$ (gas) = change in gas phase entropy; $\Delta E(\mathrm{SCF})=$ self-consistent field energy, i.e., "raw" electronic energy as computed from the SCF procedure at the triple- $\zeta$ level; $\Delta \mathrm{ZPE}=$ change in vibrational zero point energy. Coordinates of all calculated structures, vibrational frequencies, and calculated energy components are available in the online ESI. $\dagger$

\section{Results and discussion}

Based on the proposals for oxygen atom transfer from the ferryl intermediate of cytochrome $\mathbf{P} 450,{ }^{81,82}$ at least three mechanisms for alkene aziridination by the iron nitride complex can be envisioned, as summarized in Scheme 2: (1) a concerted twoelectron reaction between the iron nitride and alkene directly provides the aziridino product; (2) a cationic stepwise

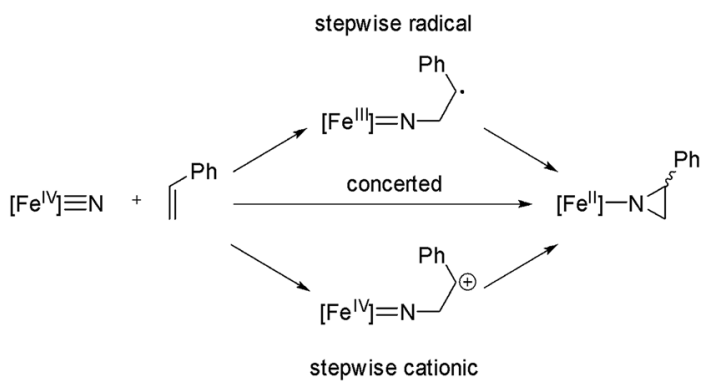

Scheme 2 mechanism provides a carbocationic intermediate that subsequently undergoes ring closure; and (3) a stepwise radical mechanism in which an iron(III) imido and an organoradical intermediate undergoes ring closure. These three mechanisms are expected to have different stereochemical outcomes. Specifically, the concerted mechanism is expected to be stereospecific, with the geometry of the alkene translated to the relative stereochemistry of the aziridino product, while the stepwise mechanisms are expected to be non-stereospecific, unless ring closure is fast relative to $\mathrm{C}-\mathrm{C}$ bond rotation. A fourth possible mechanism, which involves outer sphere electron transfer to provide an iron(III) nitride and styrene radical cation is unlikely based on the very low $\mathrm{Fe}(\mathrm{IV}) / \mathrm{Fe}$ (III) potential $\left(E_{\text {red }}<-2.5 \mathrm{~V} v s . \mathrm{Fc}^{+} / \mathrm{Fc}\right)$.

\section{Mechanistic investigations}

Interestingly, thermolysis of a 1:1 mixture of 1 and styrene does not result in complete consumption of the reagents, but instead leads to an equilibrium mixture of the reactants and the corresponding aziridino product 2 (Fig. 1). This result suggests that the aziridination reaction is reversible, allowing us to design an experiment to distinguish the concerted and stepwise mechanisms. Specifically, it is expected that stepwise mechanisms will equilibrate a non-equilibrium mixture of $\mathrm{cis}^{-}$and trans-styrenes, whereas a concerted mechanism is not expected to change the initial isomer ratio. Since steric effects limit the reactivity of $\mathbf{1}$ to primary styrenes, this hypothesis was tested using a mono- $\beta$-deuterated styrene. Consistent with our hypothesis, in addition to providing the expected aziridino product, thermolysis of 1 with a $70: 30$ mixture of trans- and cis4 -dimethylamino- $\beta$-deuterostyrenes results in styrene isomerization (Fig. 2). Styrene isomerization continues after the equilibrium ratio of $\mathbf{1}$ and the corresponding aziridino product is established, ultimately providing an equimolar mixture of the two stereoisomers. Interestingly, the relative rate of isomerization is subject to an electronic effect, as the isomerization of 4-

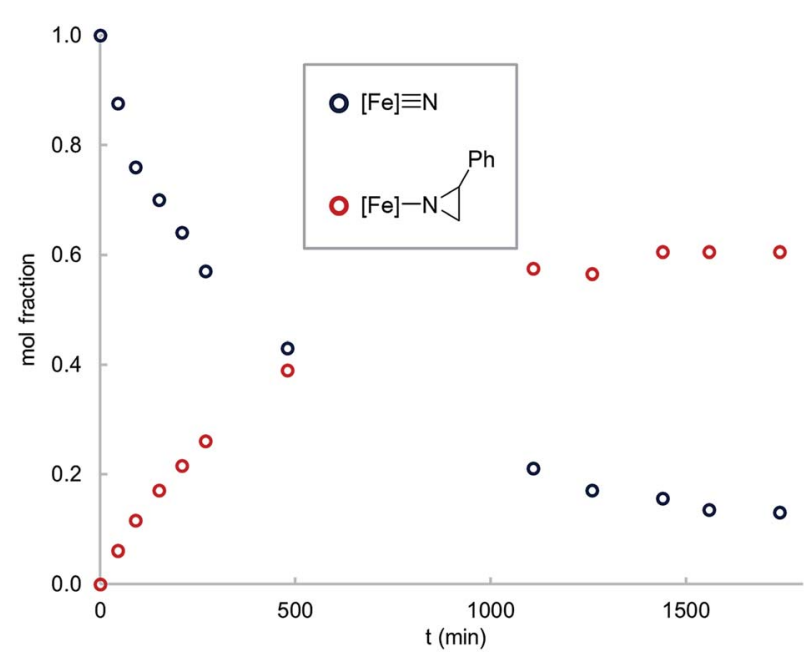

Fig. 1 Time course for the reaction of $1(0.016 \mathrm{mM})$ with styrene $(0.016 \mathrm{mM})$ in $\mathrm{C}_{6} \mathrm{D}_{6}$ solvent at $65^{\circ} \mathrm{C}$. 


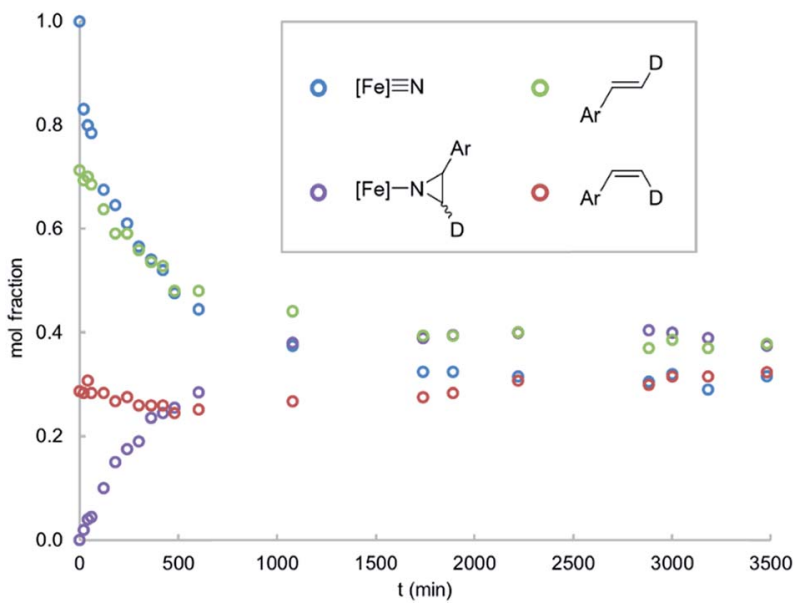

Fig. 2 Reaction time course for $1(0.016 \mathrm{mM})$ with a mixture of transand cis-4-dimethylamino- $\beta$-deuterostyrenes $(0.016 \mathrm{mM})$ in $\mathrm{C}_{6} \mathrm{D}_{6}$ solvent at $65^{\circ} \mathrm{C}$.

chloro- $\beta$-deuterostyrene is complete within minutes at room temperature, without appreciable formation of the aziridino product. Indeed, $\mathbf{1}$ is a catalyst for the isomerization 4 -chloro- $\beta$ deuterostyrene, with equilibrium ratio achieved over the course of a few hours at $65{ }^{\circ} \mathrm{C}$ in the presence of $10 \% 1$.

These results are most consistent with a stepwise pathway, assuming that the rate of ring closure is fast. However, they do not provide strong evidence into the nature of the intermediate in the stepwise mechanism, i.e. radical or cationic. We do not observe a dramatic difference in the relative reaction rate in different solvents, suggesting that radical intermediates are most likely. However, we are unable to provide definitive experimental evidence in favor of a radical intermediate as attempts at radical trapping or inhibition (e.g. with TEMPO or 9,10-dihydroanthracene) did not have a notable effect on the reaction.

A series of para-substituted styrenes was used to investigate the impact of the electronic effects on the aziridination reaction. Qualitatively, we observe that electron-withdrawing substituents increase the rate of reaction, and very electron poor styrenes, e.g. $\mathrm{CH}_{2}=\mathrm{CH}\left(p-\mathrm{CF}_{3} \mathrm{C}_{6} \mathrm{H}_{4}\right)$ react at room temperature. More quantitative insight into the electronic effect on reaction rate was obtained from the relative rates of aziridination as determined by the method of initial rates. The resulting Hammett plot shows that electron-withdrawing substituents increase the rate of reaction (Fig. 3), similarly to nitrogen atom transfer from iron(Iv) nitrides to triarylphosphines. ${ }^{83}$ There is an excellent correlation with the Hammett parameter $\sigma_{\mathrm{p}}(\rho=1.2 \pm 0.2)$ suggesting that there is negative charge development in the transition state.

In summary, the experimental investigations strongly suggest a reversible, stepwise pathway for styrene aziridination. The lack of a solvent effect as well as the increase in reaction rate with electron-withdrawing styrene substituents is reminiscent of a radical addition reaction, where the nitride has nucleophilic character. However, since the experimental results do not provide strong evidence for radical intermediate, the nature of the mechanism cannot be unambiguously determined.

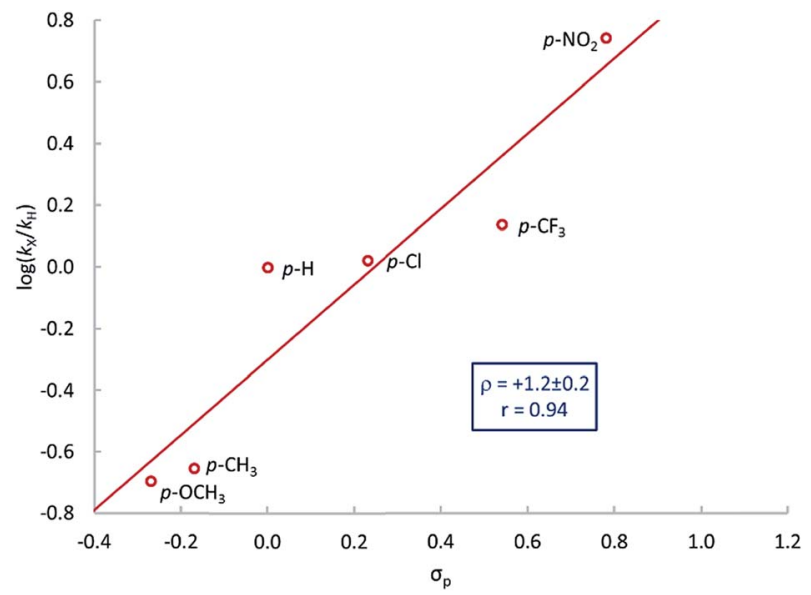

Fig. 3 Hammett plot for the reaction between 1 and $\mathrm{CH}_{2}=\mathrm{CH}(p-$ $\left.\mathrm{XC}_{6} \mathrm{H}_{4}\right)$ in $\mathrm{C}_{6} \mathrm{D}_{6}$ solvent at $65^{\circ} \mathrm{C}$.

\section{Computer models}

Given the experimental uncertainty regarding the mechanism of styrene aziridination by $\mathbf{1}$, we have undertaken a computational investigation to better elucidate the reaction pathway. In addition to the full system, we have also performed calculations on a simplified tris(carbene)borate ligand where the alkyl groups bound to the N-heterocyclic carbenes are truncated to $\mathrm{H}$ atoms. The results using the simplified model are consistent with those using the full system and in some cases the small model system was used in lieu of the bulkier model for computational simplicity. The calculations suggest that the steric bulk of the tris(carbene)borate has only a minor impact on the reaction energies and all calculated results using the small model system are consistent with those of the full model.

The ground state for $\mathbf{1}$ is the singlet $(S=0)$, which is calculated to lie $2.6 \mathrm{kcal} \mathrm{mol}^{-1}$ below the triplet $(S=1)$ state. Calculations using the M06 functional suggest that this energy gap is slightly larger at $5.3 \mathrm{kcal} \mathrm{mol}^{-1}$, but both functionals are in agreement with regards to predicted spin states for all important species and overall mechanistic conclusions of the computational investigation. The quintet state is found significantly higher in energy at $19.0 \mathrm{kcal} \mathrm{mol}^{-1}$ relative to the singlet and the d-orbital splitting for the singlet state is shown in Fig. 4 and is mechanistically irrelevant. Thus, we can conclude that the singlet and triplet states are most significant to understanding the reactivity of $\mathbf{1}$. An open-shell singlet configuration for 1 was also considered, but we were unable to locate such despite significant efforts. The orbitals shapes for the triplet are similar, but $136 \alpha$ is occupied. The orbital energies for the frontier d-orbitals for the triplet are presented alongside those of the singlet. The $C_{3 \mathrm{v}}$ geometry of the low-spin complex leads to an approximate $2+1+2$ orbital splitting with the two lowest degenerate frontier orbitals being doubly occupied. ${ }^{84}$ The LUMO is the Fe- $\mathrm{d}_{z^{2}}$ orbital, which is significantly stabilized by small $\sigma^{*}$-based interactions with the carbene fragments displaying significant amounts of admixed character from the iron $\mathrm{s}$ and $\mathrm{p}_{z}$ orbitals that reduce the net overlap with the nitrogen $\mathrm{p}_{z}$ orbital, ${ }^{13,14}$ as illustrated in Fig. 4 . This stabilization 

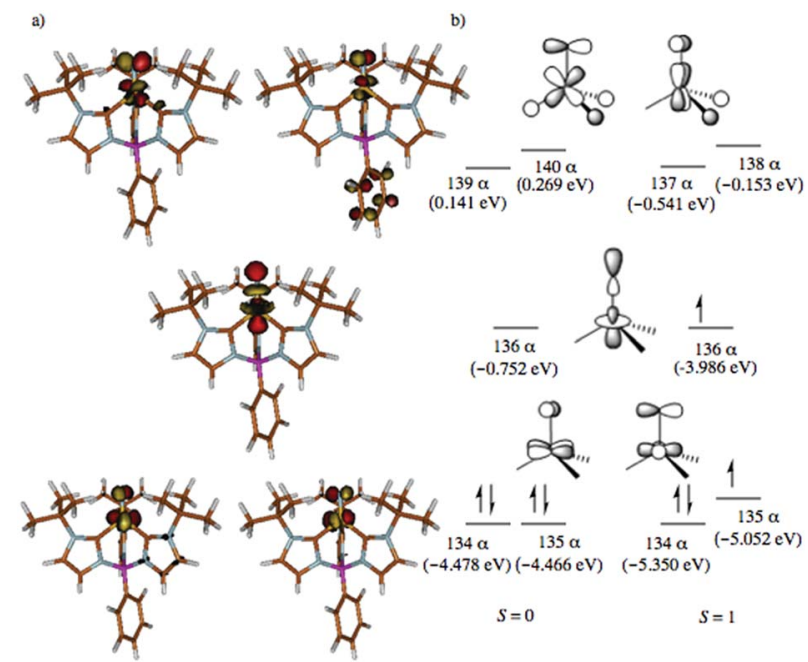
$(-0.752 \mathrm{eV})$ $(-3.986 \mathrm{eV})$

Fig. 4 (a) Isodensity surface plots (isodensity value $=0.07 \mathrm{au}$ ) of five $\mathrm{Fe}$ $3 \mathrm{~d}$-based molecular orbitals for simplified tris(carbene)borate model with (b) qualitative frontier orbital diagram for singlet $(S=0)$ and triplet $(S=1)$ states

results in the triplet state for $\mathbf{1}$ being found only slightly above the singlet ground state energetically.

The computed structures of the singlet and triplet states of $\mathbf{1}$ are shown in Fig. 5. Selected structural parameters from the crystal structure of $\mathbf{1}$ are given in the ESI $\uparrow$ for comparison and are in generally good agreement with those of the calculated structure for the closed-shell singlet state. ${ }^{\mathbf{1 3 , 4 8}}$ The triplet state exhibits several geometric distortions that result from populating the $\mathrm{Fe}-\mathrm{d}_{z^{2}}$ orbital. The Fe-nitride bond lengthens from $1.498 \AA$ to $1.558 \AA$ and the angle defined by B-Fe-N distorts significantly from linearity $\left(179^{\circ}\right)$ to $156^{\circ}$ to decrease the unfavorable overlap of the now occupied antibonding orbital. In the quintet state, the nitride ligand distorts even more to an angle of $148^{\circ}$. All of the Fe-carbene carbon bonds also are lengthened slightly as there are still some $\sigma$-type interactions with the Fe- $\mathrm{d}_{z^{2}}$ orbital. One $\mathrm{Fe}-\mathrm{C}$ distance, however, is substantially longer than the other two $\mathrm{Fe}-\mathrm{C}$ bond distances as promotion of an electron into the $\mathrm{Fe}-\mathrm{d}_{z^{2}}$ orbital results in an asymmetric occupation of the previously degenerate occupied metal-based orbitals leading to a first-order Jahn-Teller-like distortion.

The electronic structures for the different spin states of $\mathbf{1}$ provide insights into possible reaction pathways for styrene

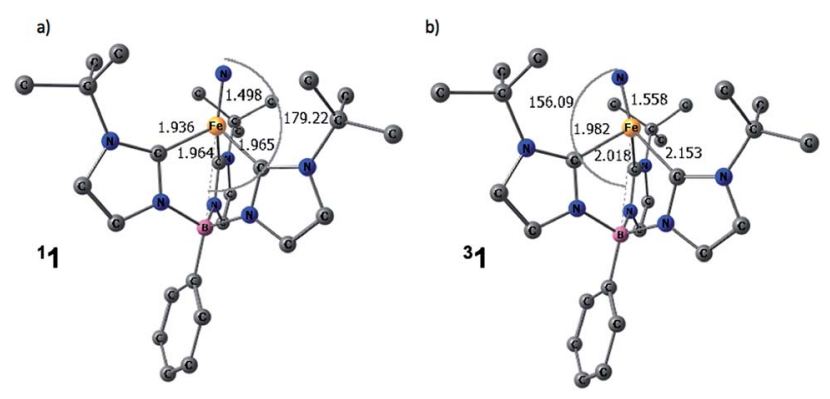

Fig. 5 Calculated structures of (a) singlet and (b) triplet spin states for 1. Hydrogen atoms are omitted for clarity. [Unit: Å] aziridination. On the ground state $S=0$ surface, a stepwise mechanism involving an open-shell singlet (OSS) has a kinetic barrier for $\mathrm{C}-\mathrm{N}$ bond formation of $27.4 \mathrm{kcal} \mathrm{mol}^{-1}$. While the experimental investigations are most consistent with a stepwise mechanism for styrene aziridination, we computationally probed the feasibility of a concerted addition of styrene. This mechanism involves two-electron transfer from the styrene $\pi$ orbital to the Fe- $\mathrm{d}_{z^{2}} \sigma^{*}$-orbital of the ground state closed-shell singlet 1. However, we were unable to locate a transition state for the concerted mechanism. Interestingly, we were also able to locate a transition state for stepwise $\mathrm{C}-\mathrm{N}$ bond formation on the closed shell singlet surface, but the barrier was found to be significantly higher in energy at $31.5 \mathrm{kcal} \mathrm{mol}^{-1}$ with respect to the singlet ground state of $\mathbf{1}$. This closed-shell TS, where the nitride ligand forms a bond to only one of the $\mathrm{sp}^{2}$ carbons of styrene, would lead to the formation of a carbocationic intermediate. Such an intermediate would also be consistent with the experimental stereochemical observations, however, we could not find a stable intermediate in our calculations on the closed shell surface. The ring closure reaction between this putative carbocation and the incipient nitrene nitrogen atom is be expected to be rapid, making this closed-shell attack of the styrene on the nitride a good approximation for the barrier in the truly concerted mechanism.

On the other hand, the low-energy triplet state that is only $2.6 \mathrm{kcal} \mathrm{mol} \mathrm{m}^{-1}$ above the singlet ground state potentially provides access to a radical type mechanism in which single electron transfer from the styrene $\pi$-orbital to the Fe- $\mathrm{d}_{z^{2}} \sigma^{*}$ orbital leads to a biradical intermediate. While experimental attempts at radical trapping did not have a significant effect on the outcome of the aziridination reaction, this does not necessarily preclude the possibility of radical intermediates. For instance, the biradical intermediate may be too short-lived to trap intermolecularly, but sufficiently long-lived to allow for $\mathrm{C}-\mathrm{C}$ bond rotation prior to transfer of the second electron concomitant with aziridine ring closure.

In good agreement with experimental results, our calculations on the full reaction coordinate also suggest that the reaction of $\mathrm{Fe}(\mathrm{Iv})$-nitride with styrene occurs in a stepwise manner, where the nitride ligand initially forms a bond to one of the alkenyl carbons of the styrene substrate. The computed reaction profile for the stepwise addition is shown in Fig. 6. The initial C-N bond formation step 1-TS, which is also expected to be rate-determining, is most favorable on the triplet potential energy surface, with a barrier of $24.6 \mathrm{kcal} \mathrm{mol}^{-1}$. This is consistent with the experimental results, where heat is required to drive the reaction and no intermediates are observed. Furthermore, the low barrier in the reverse direction (15.9 kcal mol $\mathrm{m}^{-1}$ ) is consistent with the cis/trans isomerization of the styrene substrate that is observed experimentally. Unsurprisingly, the quintet surface, which starts $19.0 \mathrm{kcal} \mathrm{mol}^{-1}$ above the singlet ground state, has a very high barrier for styrene addition of $33.8 \mathrm{kcal} \mathrm{mol}^{-1}$.

The electrophilic nitride fragment of the triplet is preferentially attacked by the $\beta$-carbon of the incoming styrene substrate as the phenyl group will help to better stabilize the radical resulting from one-electron transfer to the metal center. A study 


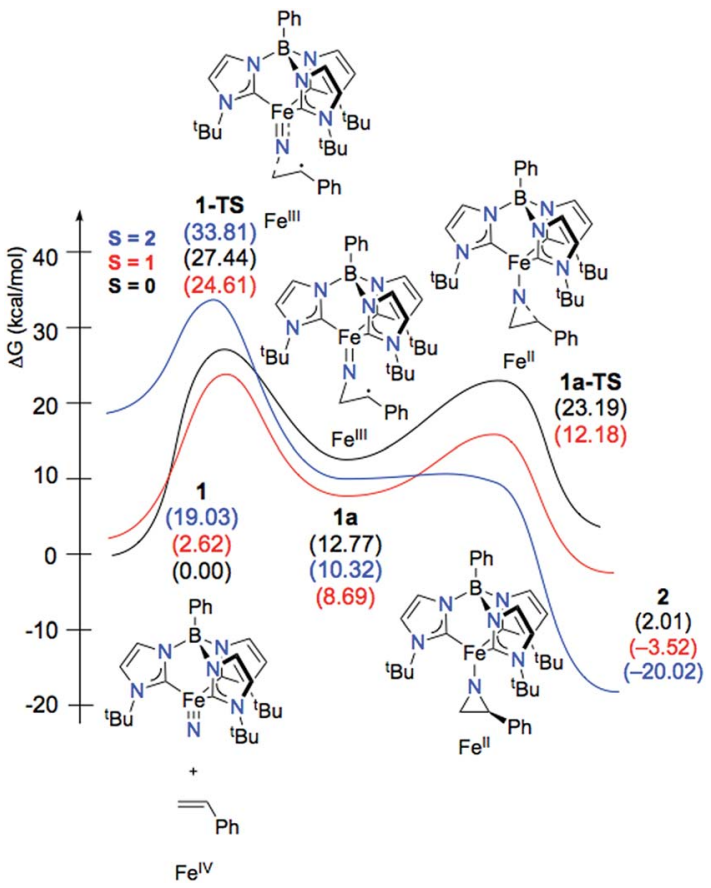

Fig. 6 Reaction profile for aziridination of styrene by an Fe(Iv)-nitride, showing closed shell singlet $(S=0)$, triplet $(S=1)$ and quintet $(S=2)$ spin surfaces. Only stepwise mechanisms are shown as concerted pathways were found to be inaccessible energetically.

using (Z)-prop-1-en-1-ylbenzene as the substrate in a small model system ( $\mathrm{R}$ groups on the NHC donors truncated to $\mathrm{H}$ ) reveals that the energetic stabilization realized by attacking the $\beta$ - rather than the $\alpha$-carbon is about $11 \mathrm{kcal} \mathrm{mol}^{-1}$ at the transition state (see the $\mathrm{ESI} \dagger$ for more details).

Scheme 3 depicts the electron density polarization and corresponding change in orbital occupation that occurs on the triplet surface during the course of the aziridination reaction prior to the intersystem crossing to the quintet product. In complex 1 , there is a small amount of $\alpha$-spin density that bleeds out onto the nitride fragment of the triplet (Mulliken spin population of 0.169). Following the formation of the $\mathrm{C}-\mathrm{N}$ bond, however, there is a significant accumulation of spin density on the nitrogen atom in intermediate ${ }^{\mathbf{3}} \mathbf{1 a}$, which is the most stable biradical intermediate found at $8.7 \mathrm{kcal} \mathrm{mol}^{-1}$ above the singlet ground state reactant ${ }^{\mathbf{1}} \mathbf{1}$. The corresponding quintet and openshell singlet intermediates, ${ }^{\mathbf{5}} \mathbf{1 a}$ and ${ }^{\mathbf{1}} \mathbf{1 a}$, are $\mathbf{1 . 6}$ and $4.1 \mathrm{kcal} \mathrm{mol}^{-1}$ higher in energy, respectively. During $\mathrm{C}-\mathrm{N}$ bond

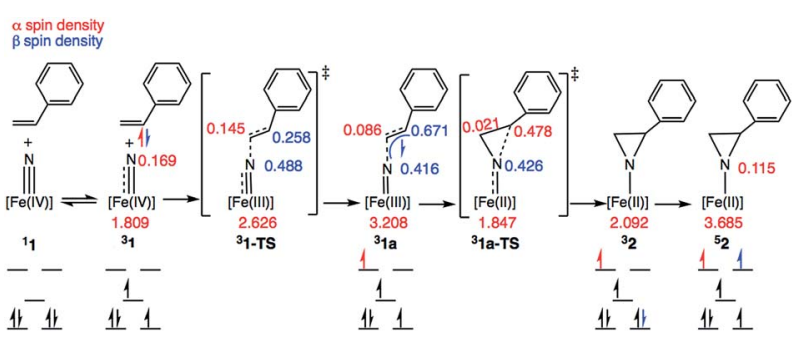

Scheme 3 formation an $\alpha$-electron is transferred from the alkene $\pi$-orbital to Fe. The Mulliken spin population consequently increases from 1.81 in ${ }^{3} \mathbf{1}$ to 3.21 in ${ }^{3} \mathbf{1 a}$ leaving an excess of $\beta$-electron density of $0.67 \beta$ on the former $\alpha$-carbon of the styrene. The remainder of the excess $\beta$-spin $(-0.42)$ has been distributed on the nitrene nitrogen atom. At the transition state for $\mathrm{C}-\mathrm{N}$ bond formation, ${ }^{3}$ 1-TS, the $\mathrm{C}-\mathrm{N}$ bond distance is $1.944 \AA$ and a majority of the $\alpha$-electron density has been transferred to Fe, which has a spin population of 2.63. Surprisingly, there is already a significant amount of $\beta$-spin present on the nitride fragment $(0.49 \beta)$ with a population of only $0.26 \beta$ on the $\alpha$ carbon of the styrene. This $\beta$-spin on the nitrene nitrogen reacts in a radical coupling mechanism with the slight excess of $\alpha$-spin of 0.15 on the $\beta$-carbon of the incoming styrene to form the $\mathrm{C}-\mathrm{N}$ bond. The structures of ${ }^{\mathbf{3}} \mathbf{1}$-TS and intermediate ${ }^{\mathbf{3}} \mathbf{1 a}$ are shown in Fig. 7. The $\mathrm{C}=\mathrm{C}$ bond distance has lengthened to $1.384 \AA$ in $^{3} \mathbf{1}$ TS from $1.338 \AA$ in free styrene and further increases to a distance of $1.498 \AA$ in ${ }^{3} \mathbf{1 a}$. Simultaneously, the Fe-N bond distance lengthens from $1.558 \AA \AA^{\circ}{ }^{3} 1$ to $1.634 \AA$ at the transition state and finally to $1.748 \AA$ in the biradical intermediate, consistent with a decrease in the bond order of the $\mathrm{Fe}-\mathrm{N}$ bond from three to two due to population of an $\mathrm{Fe}-\mathrm{N} \pi^{*}$-orbital.

After formation of intermediate ${ }^{\mathbf{3}} \mathbf{1 a}$, the second electron transfer takes place through the movement of a $\beta$-electron from the styrene $\pi$-orbital to iron, reducing the metal from $\mathrm{Fe}$ (III) to $\mathrm{Fe}(\mathrm{II})$. This electron transfer leads to an excess of $\alpha$-electron density on the $\alpha$-carbon of styrene, which subsequently couples with the excess $\beta$-electron density on the nitrene nitrogen atom in a facile radical recombination reaction. This closes the threemembered ring with a barrier of just $12.18 \mathrm{kcal} \mathrm{mol}^{-1}$ on the triplet potential energy surface. An analysis of the Mulliken spin densities at the transition state ${ }^{\mathbf{3}} \mathbf{1 a}$-TS reveals that the spin density on Fe drops from 3.208 in ${ }^{3} \mathbf{1 a}$ to 1.847 at the TS, consistent with an $S=1 \mathrm{Fe}(\mathrm{II})$ ion. The spin density on the nitrene nitrogen atom at the TS $(0.43)$ is essentially the same as in the biradical intermediate $(0.42)$. The spin population on the $\alpha$-carbon of the styrene also changes from having excess $\beta$ electron density (0.67) to surplus $\alpha$-electron density (0.48). Thus, a full $\beta$-electron has been transferred from the styrene substrate to iron. However, because the $\beta$-spin is distributed across both the nitrene nitrogen and the $\alpha$-carbon of styrene in ${ }^{\mathbf{3}} \mathbf{1 a}$, the

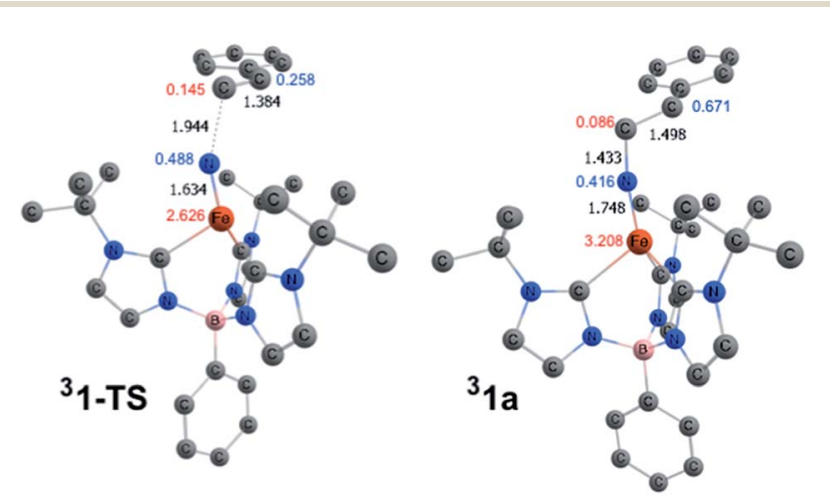

Fig. 7 Optimized structures with selected bond distances in $\AA$ of ${ }^{3} 1$-TS and ${ }^{3} 1 \mathrm{a}$. Black values indicate bond lengths in $\AA$, red values indicate $\alpha$ Mulliken spin densities, and blue values are excess $\beta$ spin densities. 
Table 1 Relative energies of ${ }^{3} 1$-TS with respect to ${ }^{1} 1$ in $\mathrm{kcal} \mathrm{mol}^{-1}$ with various para-substituted styrenes with select bond lengths and Mulliken spin densities

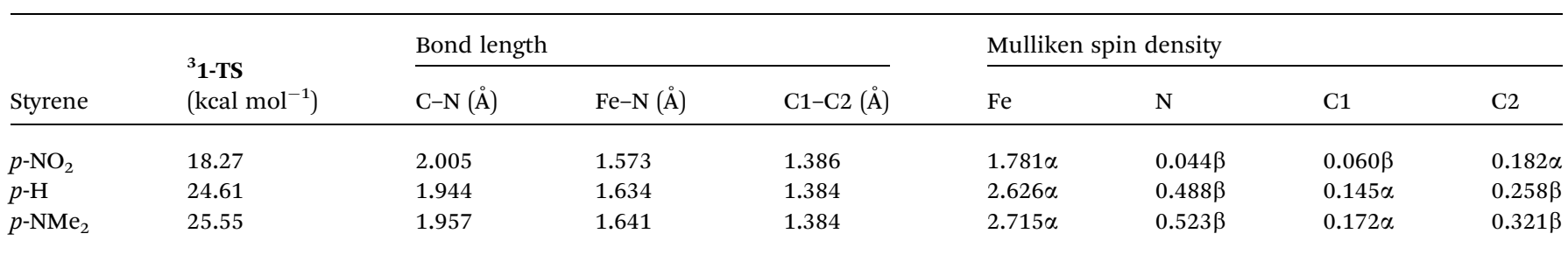

electron transfer makes styrene $\alpha$-electron density available to couple with the nitrene $\beta$-spin, thereby facilitating ring closure. In contrast to the low barrier on the triplet surface, the barrier to ring closure is calculated to be $23.2 \mathrm{kcal} \mathrm{mol}^{-1}$ on the open-shell singlet surface, which is unsurprising given that generation of the aziridino product is $2.0 \mathrm{kcal} \mathrm{mol}^{-1}$ uphill with respect to the singlet ground state of $\mathbf{1}$. Consistent with experimental results, the final aziridino complex is calculated to be most stable as a quintet, found to be $16.5 \mathrm{kcal} \mathrm{mol}^{-1}$ over the corresponding triplet species. ${ }^{13,27,57-59}$ We were unable to locate a true transition state for aziridine ring closure on the quintet surface. This is likely due to the fact that the spin densities of 0.42 on the nitrene nitrogen and 0.77 on the styrene $\alpha$-carbon in the biradical intermediate ${ }^{\mathbf{5}} \mathbf{1 a}$ facilitate a very rapid recombination event that forms the aziridine. Using the small model system described above, a linear synchronous transit scan reveals that the formation of the second $\mathrm{C}-\mathrm{N}$ bond formation is likely barrierless on the electronic potential energy surface (see the ESI $\dagger$ for more details). The intersystem crossing, which is likely helped by the metal center, may occur prior to the ring closing step, or may only occur after product formation once a large thermodynamic driving force for the quintet state is established. Our model calculations are therefore suggestive of multistate reactivity, where radical coupling between styrene and the nitride fragment proceeds more efficiently on the triplet potential energy surface compared to the ground state singlet surface. The triplet intermediate may be long-lived enough to permit $\mathrm{C}-\mathrm{C}$ bond rotation before another spin flip to the quintet state enables facile ring closure.

As quantified by the Hammett study mentioned above, electron-withdrawing $p$-substituents increase the rate of styrene aziridination. As revealed by the calculated barriers for the ratedetermining $\mathrm{C}-\mathrm{N}$ bond formation step (Table 1), the computations replicate this trend for the $p$-substituted styrenes, $p-\mathrm{NO}_{2}$ and $p-\mathrm{NMe}_{2}$, as well as the previously discussed, unsubstituted, $p$-H styrene. Importantly, analysis of the complete mechanism for all three substrates with the small model system (see above) reveals that the triplet potential energy surface is the most favorable for each substrate, allowing us to only model the ratedetermining step ${ }^{3}$ 1-TS for $p-\mathrm{NO}_{2}$ and $p-\mathrm{NMe}_{2}$ for the full system. The computational models reveal that the lowest barrier to reaction with $p-\mathrm{NO}_{2}$ styrene is just $18.3 \mathrm{kcal} \mathrm{mol}^{-1}$, which is readily overcome even under ambient conditions, consistent with the experimental observation that this substrate reacts at room temperature. The unsubstituted substrate and $p-\mathrm{NMe}_{2}$ substituted analog show much more similar kinetic barriers at
24.6 and $25.6 \mathrm{kcal} \mathrm{mol}^{-1}$, respectively, with the barrier to $\mathrm{C}-\mathrm{N}$ bond formation with $p-\mathrm{NMe}_{2}$ calculated to be slightly higher, consistent with experiment.

Interestingly, the calculations reveal that the reaction of $\mathbf{1}$ with $p-\mathrm{NO}_{2}$ styrene has a significantly different electronic structure at the transition state, whereas the other two substrates resemble each other much more closely (Table 1). Notably, the TS for $p-\mathrm{NO}_{2}$ occurs very early with respect to electron transfer. The $\mathrm{C}-\mathrm{N}$ bond distance at the transition state ${ }^{3}$ 1-TS is substantially longer $p-\mathrm{NO}_{2}(2.005 \AA)$ than for $p-\mathrm{H}(1.944$ $\AA)$ and $p-\mathrm{NMe}_{2}(1.957 \AA)$. Additionally, the iron nitride bond is essentially unactivated in the $p-\mathrm{NO}_{2}$ case with a length of 1.573 $\AA$ compared $1.558 \AA$ for ${ }^{3} \mathbf{1}$ and $1.498 \AA$ for the ground state species ${ }^{1} 1$. In contrast, $p-\mathrm{H}$ and $p-\mathrm{NMe}_{2}$ display much longer bond lengths of 1.634 and $1.641 \AA$, respectively. Whereas ${ }^{3} \mathbf{1}$-TS for the $p-\mathrm{H}$ and $p-\mathrm{NMe}_{2}$ substrates occurs much later with respect to the first electron transfer and demonstrate significant radical character on the nitride fragment and both carbon atoms of the alkene, the spin densities for $p-\mathrm{NO}_{2}$ are largely unchanged with respect to ${ }^{\mathbf{3}} \mathbf{1}$, suggesting limited electron transfer between the nitride fragment and styrene at the transition state when the substrate bears and electron-withdrawing group. Since the electron-withdrawing nitro group would typically destabilize radical formation, its presence encourages the reaction to proceed through a transition state that closely resembles the initial reactants in electronic structure. The minimal amount of electronic and structural reorganization required at the transition state for the $p-\mathrm{NO}_{2}$ substrate likely helps facilitate a faster rate of reaction compared to the unsubstituted and $p-\mathrm{NMe}_{2}$ substrates where larger structural changes accompany the development of significant radical cation character at the transition state.

\section{Conclusions}

A combined experimental and computational investigation into the aziridination of styrenes by the Fe(Iv) nitride complex 1 reveals that the reaction proceeds as an asynchronous addition of the styrene to the nitride moiety. While we were able to locate a pathway leading to aziridine formation on the same spin state surface as the singlet ground state for $\mathbf{1}$, the most energetically favorable mechanism actually occurs on the triplet surface. This multistate character therefore results in the rate determining step being on a different spin surface than the reactant ground state. The triplet state imparts slight nucleophilic nitridyl character to the nitride fragment, thereby promoting the 
stepwise radical addition of the styrene. It is likely that the styrene substrate also plays a role in stabilizing this radical character during the reaction. The accessibility of a spin state surface with a lower barrier towards $\mathrm{C}-\mathrm{N}$ bond formation is therefore critical for facilitating styrene aziridination.

This combined experimental and computational investigation provides the first evidence for multistate reactivity by a transition metal nitride complex. Despite the differences in bonding with the related oxo and imido ligands (e.g. ligand charge, covalency), complex $\mathbf{1}$ is able to access a different spin state surface that facilitates the aziridination reactivity. It is worth comparing the mechanism of alkene aziridination by $\mathbf{1}$, which involves nitrogen atom transfer, with that determined for high valent iron porphyrin tosylimido complexes, which involve nitrene transfer. In the latter case, multistate reactivity requires access to lower spin states, ${ }^{33}$ whereas access to a higher spin state is required to facilitate styrene aziridination by 1 . This difference in spin state effects, which stems from the different ground state electronic structures, provides a rationale for the differential electronic selectivity of $\mathbf{1}$ and iron porphyrin complexes. Thus, while electron poor styrenes that better stabilize the high spin transition state react more rapidly for $\mathbf{1}$, in the case of iron porphyrins aziridination is postulated to be faster with more electron rich styrenes. ${ }^{33}$

The mechanistic insights from this study also suggest strategies for rationally tuning the aziridination reaction. For example, ligand design strategies that increase the nitridyl radical character (e.g. by decreasing the relative energy of the

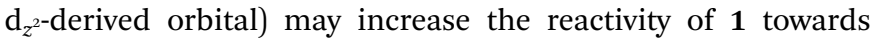
alkene substrates that are less stabilizing of the radical character. Substrates bearing electron-withdrawing groups require minimal electronic reorganization at the rate-determining transition state, leading to faster reaction rates. Moreover, the stepwise nature of the reaction mechanism also suggests a strategy for stereospecific aziridination, where chiral substituents on the tris(carbene)borate ligands are expected to impart stereocontrol on the ring closing step. Studies towards exploiting these novel insights are underway in our laboratories.

\section{Conflicts of interest}

There are no conflicts to declare.

\section{Acknowledgements}

SBM and JMS acknowledge support from IU and DOE-BES (DEFG02-08ER15996). We thank the Institute for Basic Science in Korea for financial support (IBS-R10-D1).

\section{Notes and references}

1 A. Padwa, Aziridines and Azirines: Monocyclic, in Comprehensive Heterocyclic Chemistry III, ed. C. A. Ramsden, E. F. V. Scriven and R. J. K. Taylor, Elsevier, Oxford, 2008, pp. 1-104.

2 J. T. Njardarson, Catalytic Ring Expansion Adventures, Synlett, 2013, 24, 787-803.
3 A. L. Cardoso and T. M. V. D. Pinho e Melo, Aziridines in Formal [3 +2$]$ Cycloadditions: Synthesis of Five-Membered Heterocycles, Eur. J. Org. Chem., 2012, 2012, 6479-6501.

$4 \mathrm{H}$. Pellissier, Recent Developments in Asymmetric Aziridination, Tetrahedron, 2010, 66, 1509-1555.

5 C. Botuha, F. Chemla, F. Ferreira and A. Pérez-Luna, Aziridines in Natural Product Synthesis, in Heterocycles in Natural Product Synthesis, ed. K. C. Majumdar and S. K. Chattopadhyay, 2011.

6 C. J. Thibodeaux, W.-C. Chang and H.-W. Liu, Enzymatic Chemistry of Cyclopropane, Epoxide, and Aziridine Biosynthesis, Chem. Rev., 2012, 112, 1681-1709.

7 I. D. G. Watson, L. Yu and A. K. Yudin, Advances in Nitrogen Transfer Reactions Involving Aziridines, Acc. Chem. Res., 2006, 39, 194-206.

8 T. G. Driver, Recent Advances in Transition Metal-Catalyzed $N$-atom Transfer Reactions of Azides, Org. Biomol. Chem., 2010, 8, 3831-3846.

9 D. A. Evans, M. M. Faul, M. T. Bilodeau, B. A. Anderson and D. M. Barnes, Bis(oxazoline)-Copper Complexes as Chiral Catalysts for the Enantioselective Aziridination of Olefins, J. Am. Chem. Soc., 1993, 115, 5328-5329.

10 Z. Li, K. R. Conser and E. N. Jacobsen, Asymmetric Alkene Aziridination with Readily Available Chiral Diimine-based Catalysts, J. Am. Chem. Soc., 1993, 115, 5326-5327.

11 B. M. Trost and G. Dong, New Class of Nucleophiles for Palladium-Catalyzed Asymmetric Allylic Alkylation. Total Synthesis of Agelastatin A, J. Am. Chem. Soc., 2006, 128, 6054-6055.

12 S. Cenini, S. Tollari, A. Penoni and C. Cereda, Catalytic Amination of Unsaturated Hydrocarbons: Reactions of $p$ nitrophenylazide with Alkenes Catalysed by Metalloporphyrins, J. Mol. Catal. A, 1999, 137, 135-146.

13 S. A. Cramer and D. M. Jenkins, Synthesis of Aziridines from Alkenes and Aryl Azides with a Reusable Macrocyclic Tetracarbene Iron Catalyst, J. Am. Chem. Soc., 2011, 133, 19342-19345.

14 D. M. Jenkins, Atom-Economical $\mathrm{C}_{2}+\mathrm{N}_{1}$ Aziridination: Progress towards Catalytic Intermolecular Reactions Using Alkenes and Aryl Azides, Synlett, 2012, 23, 1267-1270.

15 S. A. Cramer, R. Hernández Sánchez, D. F. Brakhage and D. M. Jenkins, Probing the Role of an $\mathrm{Fe}^{\mathrm{IV}}$ Tetrazene in Catalytic Aziridination, Chem. Commun., 2014, 50, 1396713970.

16 J. L. Jat, M. P. Paudyal, H. Gao, Q.-L. Xu, M. Yousufuddin, D. Devarajan, D. H. Ess, L. Kürti and J. R. Falck, Direct Stereospecific Synthesis of Unprotected $\mathrm{N}-\mathrm{H}$ and $\mathrm{N}-\mathrm{Me}$ Aziridines from Olefins, Science, 2014, 343, 61-65.

17 Z. Ma, Z. Zhou and L. Kürti, Direct and Stereospecific Synthesis of $\mathrm{N}-\mathrm{H}$ and $\mathrm{N}$-Alkyl Aziridines from Unactivated Olefins Using Hydroxylamine-O-Sulfonic Acids, Angew. Chem., Int. Ed., 2017, 56, 9886-9890.

18 C. L. Keller, J. L. Kern, B. D. Terry, S. Roy and D. M. Jenkins, Catalytic Aziridination with Alcoholic Substrates via a Chromium Tetracarbene Catalyst, Chem. Commun., 2018, 54, 1429-1432. 
19 J. J. Scepaniak, M. D. Fulton, R. P. Bontchev, E. N. Duesler, M. L. Kirk and J. M. Smith, Structural and Spectroscopic Characterization of an Electrophilic Iron Nitrido Complex, J. Am. Chem. Soc., 2008, 130, 10515-10517.

20 S. B. Muñoz, W.-T. Lee, D. A. Dickie, J. J. Scepaniak, D. Subedi, M. Pink, M. D. Johnson and J. M. Smith, Styrene Aziridination by Iron(Iv) Nitrides, Angew. Chem., Int. Ed., 2015, 54, 10600-10603.

21 S. N. Brown, Insertion of a Metal Nitride into CarbonCarbon Double Bonds, J. Am. Chem. Soc., 1999, 121, 97529753.

22 A. G. Maestri, S. D. Taylor, S. M. Schuck and S. N. Brown, Cleavage of Conjugated Alkenes by Cationic Osmium Nitrides: Scope of the Reaction and Dynamics of the Azaallenium Products, Organometallics, 2004, 23, 1932-1946.

23 J. M. Smith, Reactive Transition Metal Nitride Complexes, in Progress in Inorganic Chemistry, ed. K. D. Karlin, Wiley, 2014.

24 A. G. Maestri, K. S. Cherry, J. J. Toboni and S. N. Brown, [4+ 1] Cycloadditions of Cyclohexadienes with Osmium Nitrides, J. Am. Chem. Soc., 2001, 123, 7459-7460.

25 W. L. Man, W. W. Y. Lam, H. K. Kwong, S. M. Yiu and T. C. Lau, Ligand-Accelerated Activation of Strong $\mathrm{C}-\mathrm{H}$ Bonds of Alkanes by a (Salen)ruthenium(VI)-Nitrido Complex, Angew. Chem., Int. Ed., 2012, 51, 9101-9104.

26 W. L. Man, J. Xie, P. K. Lo, W. Y. Lam William, S. M. Yiu, K. C. Lau and T. C. Lau, Functionalization of Alkynes by a (Salen)ruthenium(VI) Nitrido Complex, Angew. Chem., Int. Ed., 2014, 53, 8463-8466.

27 J. Xie, W.-L. Man, C.-Y. Wong, X. Chang, C.-M. Che and T.-C. Lau, Four-Electron Oxidation of Phenols to $p$ Benzoquinone Imines by a (Salen)ruthenium(VI) Nitrido Complex, J. Am. Chem. Soc., 2016, 138, 5817-5820.

28 W.-H. Chiu, W.-M. Cheung, M.-C. Chong, H. H.-Y. Sung, I. D. Williams and W.-H. Leung, Tetranuclear Ruthenium Cyclopentadienyl and Pentamethylcyclopentadienyl Complexes Containing Bridging Nitrido Ligands, Organometallics, 2018, 37, 1034-1039.

29 (a) C. E. Laplaza and C. C. Cummins, Science, 1995, 268, 861863; (b) Q. Liao, A. Cavaille, N. Saffon-Merceron and N. Mezailles, Angew. Chem., Int. Ed., 2016, 55, 1121211216; (c) T. J. Hebden, R. R. Schrock, M. K. Takase and P. Mueller, Chem. Commun., 2012, 48, 1851-1853; (d) I. Klopsch, M. Finger, C. Wuertele, B. Milde, D. B. Werz and S. Schneider, J. Am. Chem. Soc., 2014, 136, 6881-6883; (e) K. Arashiba, A. Eizawa, H. Tanaka, K. Nakajima, K. Yoshizawa and Y. Nishibayashi, Bull. Chem. Soc. Jpn., 2017, 90, 1111-1118; (f) B. M. Lindley, R. S. van Alten, M. Finger, F. Schendzielorz, C. Wuertele, A. J. M. Miller, I. Siewert and S. Schneider, J. Am. Chem. Soc., 2018, 140, 7922-7935.

30 M. Nakanishi, A.-F. Salit and C. Bolm, Iron-Catalyzed Aziridination Reactions, Adv. Synth. Catal., 2008, 350, 1835-1840.

31 A. C. Mayer, A.-F. Salit and C. Bolm, Iron-Catalysed Aziridination Reactions Promoted by an Ionic Liquid, Chem. Commun., 2008, 5975-5977.
32 S. Liang and M. P. Jensen, Half-Sandwich Scorpionates as Nitrene Transfer Catalysts, Organometallics, 2012, 31, 80558058.

33 E. T. Hennessy, R. Y. Liu, D. A. Iovan, R. A. Duncan and T. A. Betley, Iron-mediated Intermolecular N-group Transfer Chemistry with Olefinic Substrates, Chem. Sci., 2014, 5, 1526-1532.

34 (a) Y. Moreau, H. Chen, E. Derat, H. Hirao, C. Bolm and S. Shaik, NR Transfer Reactivity of Azo-Compound I of P450. How Does the Nitrogen Substituent Tune the Reactivity of the Species toward $\mathrm{C}-\mathrm{H}$ and $\mathrm{C}=\mathrm{C}$ Activation?, J. Phys. Chem. B, 2007, 111, 10288-10299; (b) R. Patra, G. Coin, L. Castro, P. Dubourdeaux, M. Clémancey, J. Pécaut, C. Lebrun, P. Maldivi and J.-M. Latour, Rational Design of Fe Catalysts for Olefin Aziridination through DFT-Based Mechanistic Analysis, Catal. Sci. Technol., 2017, 7, 4388-4400.

35 C. Damiano, D. Intrieri and E. Gallo, Aziridination of Alkenes Promoted by Iron or Ruthenium Complexes, Inorg. Chim. Acta, 2018, 470, 51-67.

36 K. L. Klotz, L. M. Slominski, M. E. Riemer, J. A. Phillips and J. A. Halfen, Mechanism of the Iron-Mediated Alkene Aziridination Reaction: Experimental and Computational Investigations, Inorg. Chem., 2009, 48, 801-803.

37 C.-M. Che and J.-S. Huang, Metalloporphyrin-based Oxidation Systems: From Biomimetic Reactions to Application in Organic Synthesis, Chem. Commun., 2009, 3996-4015.

38 K. Schröder, K. Junge, B. Bitterlich and M. Beller, FeCatalyzed Oxidation Reactions of Olefins, Alkanes, and Alcohols: Involvement of Oxo- and Peroxo Complexes, Top. Organomet. Chem., 2011, 33, 83-109.

39 H. Srour, P. Le Maux, S. Chevance and G. Simonneaux, Metal-Catalyzed Asymmetric Sulfoxidation, Epoxidation and Hydroxylation by Hydrogen Peroxide, Coord. Chem. Rev., 2013, 257, 3030-3050.

40 X. Huang and J. T. Groves, Oxygen Activation and Radical Transformations in Heme Proteins and Metalloporphyrins, Chem. Rev., 2018, 118, 2491-2553.

41 J. T. Groves, T. E. Nemo and R. S. Myers, Hydroxylation and Epoxidation Catalyzed by Iron-Porphine Complexes. Oxygen Transfer from Iodosylbenzene, J. Am. Chem. Soc., 1979, 101, 1032-1033.

42 J. T. Groves, R. C. Haushalter, M. Nakamura, T. E. Nemo and B. J. Evans, High-valent Iron-Porphyrin Complexes Related to Peroxidase and Cytochrome P-450, J. Am. Chem. Soc., 1981, 103, 2884-2886.

$43 \mathrm{H}$. Fujii, Electronic Structure and Reactivity of High-valent Oxo Iron Porphyrins, Coord. Chem. Rev., 2002, 226, 51-60.

44 M. H. Lim, J.-U. Rohde, A. Stubna, M. R. Bukowski, M. Costas, R. Y. N. Ho, E. Münck, W. Nam and L. Que, $\mathrm{AnFe}^{\mathrm{IV}}=\mathrm{O}$ Complex of a Tetradentate Tripodal Nonheme Ligand, Proc. Natl. Acad. Sci. U. S. A., 2003, 100, 3665.

45 J. Bautz, P. Comba, C. opezdeLaorden, M. Menzel and G. Rajaraman, Biomimetic High-Valent Non-Heme Iron Oxidants for the cis-Dihydroxylation and Epoxidation of Olefins, Angew. Chem., Int. Ed., 2007, 46, 8067-8070. 
46 J. Annaraj, S. Kim, M. S. Seo, Y.-M. Lee, Y. Kim, S.-J. Kim, Y. S. Choi, H. G. Jang and W. Nam, An Iron(II) Complex with a $\mathrm{N}_{3} \mathrm{~S}_{2}$ Thioether Ligand in the Generation of an Iron(Iv)-oxo Complex and its Reactivity in Olefin Epoxidation, Inorg. Chim. Acta, 2009, 362, 1031-1034.

47 A. Thibon, J.-F. Bartoli, S. Bourcier and F. Banse, Mononuclear Iron Complexes Relevant to Nonheme Iron Oxygenases. Synthesis, Characterizations and Reactivity of Fe-Oxo and Fe-Peroxo Intermediates, Dalton Trans., 2009, 9587-9594.

48 W. Ye, R. J. Staples and E. V. Rybak-Akimova, Oxygen Atom Transfer Mediated by an Iron(Iv)/Iron(II) Macrocyclic Complex Containing Pyridine and Tertiary Amine Donors, J. Inorg. Biochem., 2012, 115, 1-12.

49 W. Nam, High-Valent Iron(Iv)-Oxo Complexes of Heme and Non-Heme Ligands in Oxygenation Reactions, Acc. Chem. Res., 2007, 40, 522-531.

50 W. J. Song, Y. O. Ryu, R. Song and W. Nam, Oxoiron(Iv) Porphyrin $\pi$-Cation Radical Complexes with a Chameleon Behavior in Cytochrome P450 Model Reactions, J. Bio. Inorg. Chem., 2005, 10, 294-304.

51 K. K. Singh, M. K. Tiwari, B. B. Dhar, K. Vanka and S. Sen Gupta, Mechanism of Oxygen Atom Transfer from $\mathrm{Fe}^{\mathrm{V}}(\mathrm{O})$ to Olefins at Room Temperature, Inorg. Chem., 2015, 54, 6112-6121.

52 J. P. Collman, T. Kodadek and J. I. Brauman, Oxygenation of Styrene by Cytochrome P-450 Model Systems. A Mechanistic Study, J. Am. Chem. Soc., 1986, 108, 2588-2594.

53 A. J. Castellino and T. C. Bruice, Intermediates in the Epoxidation of Alkenes by Cytochrome P-450 Models. 1. cis-Stilbene as a Mechanistic Probe, J. Am. Chem. Soc., 1988, 110, 158-162.

54 D. Schröder, S. Shaik and H. Schwarz, Two-State Reactivity as a New Concept in Organometallic Chemistry, Acc. Chem. Res., 2000, 33, 139-145.

55 S. P. de Visser, F. Ogliaro, N. Harris and S. Shaik, Multi-State Epoxidation of Ethene by Cytochrome P450: A Quantum Chemical Study, J. Am. Chem. Soc., 2001, 123, 3037-3047.

56 S. Shaik, S. P. de Visser, F. Ogliaro, H. Schwarz and D. Schröder, Two-State Reactivity Mechanisms of Hydroxylation and Epoxidation by Cytochrome P-450 Revealed by Theory, Curr.Opin. Chem. Biol., 2002, 6, 556-567.

57 D. Kumar, B. Karamzadeh, G. N. Sastry and S. P. de Visser, What Factors Influence the Rate Constant of Substrate Epoxidation by Compound I of Cytochrome P450 and Analogous Iron(Iv)-Oxo Oxidants?, J. Am. Chem. Soc., 2010, 132, 7656-7667.

58 D. Kumar, R. Latifi, S. Kumar, E. V. Rybak-Akimova, M. A. Sainna and S. P. de Visser, Rationalization of the Barrier Height for $p$-Z-styrene Epoxidation by Iron(Iv)-Oxo Porphyrin Cation Radicals with Variable Axial Ligands, Inorg. Chem., 2013, 52, 7968-7979.

59 Y. Ren, K. Cheaib, J. Jacquet, H. Vezin, L. Fensterbank, M. Orio, S. Blanchard and M. Desage-El Murr, CopperCatalyzed Aziridination with Redox-Active Ligands: Molecular Spin Catalysis, Chem.-Eur. J., 2018, 24, 5086-5090.
60 J. Liu, L. Hu, L. Wang, H. Chen and L. Deng, An Iron(II) Ylide Complex as a Masked Open-Shell Iron Alkylidene Species in Its Alkylidene-Transfer Reactions with Alkenes, J. Am. Chem. Soc., 2017, 139, 3876-3888.

61 R. G. Parr and W. Yang, Density Functional Theory of Atoms and Molecules, Oxford University Press, New York, 1989.

62 T. Ziegler, Approximate Density Functional Theory as a Practical Tool in Molecular Energetics and Dynamics, Chem. Rev., 1991, 91, 651-667.

63 Jaguar 8.1, Schrödinger, Inc., New York, NY, 2014.

64 S. Grimme, J. Antony, S. Ehrlich and H. Krieg, A Consistent and Accurate $a b$ initio Parametrization of Density Functional Dispersion Correction (DFT-D) for the 94 Elements H-Pu, J. Chem. Phys., 2010, 132, 154104.

65 A. D. Becke, Density-Functional Exchange-Energy Approximation with Correct Asymptotic Behavior, Phys. Rev. A, 1988, 38, 3098-3100.

66 A. D. Becke, Density-Functional Thermochemistry. III. The Role of Exact Exchange, J. Chem. Phys., 1993, 98, 5648-5652.

67 C. Lee, W. Yang and R. G. Parr, Development of the ColleSalvetti Correlation-Energy Formula into a Functional of the Electron Density, Phys. Rev. B, 1988, 37, 785-789.

68 J. C. Slater, Quantum Theory of Molecules and Solids: The SelfConsistent Field for Molecules and Solids, McGraw-Hill, New York, 1974, vol. 4.

69 S. H. Vosko, L. Wilk and M. Nusair, Accurate SpinDependent Electron Liquid Correlation Energies for Local Spin-Density Calculations - A Critical Analysis, Can. J. Phys., 1980, 58, 1200-1211.

70 P. J. Hay and W. R. Wadt, Ab initio Effective Core Potentials for Molecular Calculations - Potentials for the TransitionMetal Atoms Sc to Hg, J. Chem. Phys., 1985, 82, 270-283.

71 W. R. Wadt and P. J. Hay, Ab initio Effective Core Potentials for Molecular Calculations - Potentials for Main Group Elements Na to Bi, J. Chem. Phys., 1985, 82, 284-298.

72 P. J. Hay and W. R. Wadt, Ab initio Effective Core Potentials for Molecular Calculations - Potentials for $\mathrm{K}$ to $\mathrm{Au}$ Including the Outermost Core Orbitals, J. Chem. Phys., 1985, 82, 299310.

73 T. H. Dunning Jr, Gaussian Basis Sets for Use in Correlated Molecular Calculations. I. The Atoms Boron through Neon and Hydrogen, J. Chem. Phys., 1989, 90, 1007-1023.

74 Y. Zhao and D. G. Truhlar, The M06 Suite of Density Functionals for Main Group Thermochemistry, Thermochemical Kinetics, Noncovalent Interactions, Excited States, and Transition Elements: Two New Functionals and Systematic Testing of Four M06-Class Functionals and 12 Other Functionals, Theor. Chem. Acc., 2008, 120, 215-241.

75 B. Marten, K. Kim, C. Cortis, R. A. Friesner, R. B. Murphy, M. N. Ringnalda, D. Sitkoff and B. Honig, New Model for Calculation of Solvation Free Energies: Correction of SelfConsistent Reaction Field Continuum Dielectric Theory for Short-Range Hydrogen-Bonding Effects, J. Phys. Chem., 1996, 100, 11775-11788.

76 M. Friedrichs, R. H. Zhou, S. R. Edinger and R. A. Friesner, Poisson-Boltzmann Analytical Gradients for Molecular 
Modeling Calculations, J. Phys. Chem. B, 1999, 103, 30573061.

77 S. R. Edinger, C. Cortis, P. S. Shenkin and R. A. Friesner, Solvation Free Energies of Peptides: Comparison of Approximate Continuum Solvation Models With Accurate Solution of the Poisson-Boltzmann Equation, J. Phys. Chem. B, 1997, 101, 1190-1197.

78 A. A. Rashin and B. Honig, Reevaluation of the Born Model of Ion Hydration, J. Phys. Chem., 1985, 89, 5588-5593.

79 L. Noodleman, Valence Bond Description of Antiferromagnetic Coupling in Transition Metal Dimers, $J$. Chem. Phys., 1981, 74, 5737-5743.

80 L. Noodleman and E. R. Davidson, Ligand Spin Polarization and Antiferromagnetic Coupling in Transition Metal Dimers, Chem. Phys., 1986, 109, 131-143.

81 L. Noodleman, T. Lovell, W.-G. Han, J. Li and F. Himo, Quantum Chemical Studies of Intermediates and Reaction
Pathways in Selected Enzymes and Catalytic Synthetic Systems, Chem. Rev., 2004, 104, 459-508.

82 F. P. Guengerich and T. L. Macdonald, Chemical Mechanisms of Catalysis by Cytochromes P-450: A Unified View, Acc. Chem. Res., 1984, 17, 9-16.

83 P. R. Ortiz de Montellano, Substrate Oxidation by Cytochrome P450 Enzymes, in Cytochrome P450: Structure, Mechanism, and Biochemistry, ed. P. R. Ortiz de Montellano, Springer International Publishing, Cham, 2015, pp. 111176.

84 L. Bucinsky, M. Breza, W.-T. Lee, A. K. Hickey, D. A. Dickie, I. Nieto, J. A. DeGayner, T. D. Harris, K. Meyer, J. Krzystek, A. Ozarowski, J. Nehrkorn, A. Schnegg, K. Holldack, R. H. Herber, J. Telser and J. M. Smith, Spectroscopic and Computational Studies of Spin States of Iron(Iv) Nitrido and Imido Complexes, Inorg. Chem., 2017, 56, 4751-4768. 